Portland State University

PDXScholar

\title{
Increasing Youths' Participation in Team-Based Treatment Planning: The Achieve My Plan Enhancement for Wraparound
}

\author{
Janet S. Walker \\ Portland State University, janetw@pdx.edu \\ Celeste L. Seibel \\ Portland State University \\ Sharice Jackson \\ Portland State University
}

Follow this and additional works at: https://pdxscholar.library.pdx.edu/socwork_fac

Part of the Social Work Commons

Let us know how access to this document benefits you.

\section{Citation Details}

Walker, Janet S.; Seibel, Celeste L.; and Jackson, Sharice, "Increasing Youths' Participation in Team-Based Treatment Planning: The Achieve My Plan Enhancement for Wraparound" (2017). Social Work Faculty Publications and Presentations. 170.

https://pdxscholar.library.pdx.edu/socwork_fac/170

This Post-Print is brought to you for free and open access. It has been accepted for inclusion in Social Work Faculty Publications and Presentations by an authorized administrator of PDXScholar. Please contact us if we can make this document more accessible: pdxscholar@pdx.edu. 
[This is an Accepted Manuscript of an article published by Springer in Journal of Child and Family Studies on May 3, 2017, available online: http://link.springer.com/article/10.1007/s10826-017-0738-0]

\title{
Increasing Youths' Participation in Team-Based Treatment Planning: The Achieve My Plan Enhancement for Wraparound
}

\author{
Janet S. Walker, Celeste L. Seibel, \& Sharice Jackson
}

\begin{abstract}
Wraparound is a frequently implemented approach for providing individualized, community-based care for children and adolescents with serious mental health conditions and, typically, involvement in multiple childand family-serving systems. Both Wraparound's principles and its theory of change stress the importance of youths' active participation throughout. However, research focusing on the experiences of youth in Wraparound indicates that they are often not particularly engaged in the process or participating actively with their teams, and the findings point to a lack of alliance between the young people and their teams. This article describes a randomized study testing the Achieve My Plan (AMP) enhancement for Wraparound, which is intended to increase young people's satisfaction, active engagement and self-determined participation in Wraparound, as well as their alliance with the team. Study findings showed that, relative to youth who received "as usual" Wraparound, young people who received Wraparound with the AMP enhancement participated more-and in a more active and self-determined manner-with their teams. They also rated their alliance with their Wraparound teams significantly higher. Furthermore, adult team members in the intervention condition rated team meetings as being more productive, and they were more likely to say that the AMP meetings were "much better than usual" team meetings. Findings support the idea that it is possible-using a low-cost, low- "dose" intervention-to enhance young people's self-determination and their engagement in Wraparound without detracting from team functioning or the satisfaction of other team members.
\end{abstract}

\section{Introduction}

Wraparound is a frequently implemented, comprehensive approach for planning and providing individualized, community-based care for children and adolescents with serious mental health conditions and, typically, involvement in multiple childand family-serving systems (Walker et al. 2008). According to estimates from the most recent state survey (Sather and Bruns 2016), Wraparound is now available in almost every state, with at least 75,000 young people and their families enrolled in close to 700 Wraparound initiatives in the United States. The

core work of Wraparound is carried out by a team that includes the child and family members, service providers that work with the child and family, and people from the family's network of social support (Bruns et al. 2010). The work of the Wraparound team is typically facilitated by a Wraparound care coordinator, who is responsible for ensuring that team members work together collaboratively to develop, implement, and monitor an individualized plan of care that coordinates and adjusts services and supports for the child/youth and family. 
While the principles of Wraparound call for a collaborative team process, the exact nature of the collaboration is somewhat unique. The Wraparound principles stress that youth and family perspectives are to be prioritized in determining the primary needs that the Wraparound team will address, as well as the service and support strategies to be included in the Wraparound plan of care (Bruns et al. 2004). Theoretical models that explain how Wraparound produces results (Walker and Matarese 2011; Walker and Schutte 2004) emphasize the importance of engagement and, in particular, of carefully and thoroughly exploring strengths, needs, and goals from the perspective of the youth and family members. Theory also stresses that, as teamwork progresses, family and youth perspectives must continue to be prioritized as the team implements and monitors the plan of care, continually evaluating the extent to which the service and support strategies included in the plan are being successful in meeting needs and achieving goals. In short, the theory proposes that Wraparound is effective-and different from other forms or care planning-because it unites the young person, the family, service providers and other team members around a shared vision regarding what's going well, what needs to be different, and how well strategies for change are working. Because of this alignment of perspectives, the team is collectively oriented toward the most important needs, and able to address these needs at a more profound and holistic level than usual treatment planning.

However, research focusing on the experiences of youth in Wraparound indicates that they may not be particularly engaged in the process or participating actively with their teams. (Haber et al. 2012; Walker et al. 2009, 2012; Walker and Schutte 2005). A consistent finding across these studies is that youth are less satisfied than other stakeholders regarding their experiences with Wraparound overall. In the earliest study to examine youth participation, Walker and Schutte (2005) found that young people were often not present at their Wraparound team meetings at all. When they were present, young people's ratings not only of their satisfaction with the meeting, but also of their level of comfort during the meeting, were significantly lower than other participants' ratings. Furthermore, one of the top challenges identified by service providers in the study was productively including the young person in the meeting. Haber et al. (2012) found that, compared to other team members, youth tended to see their Wraparound teams as less cohesive and as implementing fewer core features of Wraparound teamwork best practices. Walker and colleagues (2012) reported data regarding youth participation and engagement from three separate studies. The first of these was a national study of Wraparound fidelity, which found that youth ratings of their active participation in Wraparound were lower than ratings provided by caregivers (i.e., parents or other guardians). The second study, which reported on findings from a different study of Wraparound fidelity in Nevada, found that youth reported a lower level of involvement in Wraparound planning relative to their caregivers. The final study analyzed video-recordings of Wraparound team meetings taking place in a high school, and found that, on average, youth spoke continuously-without being interrupted by an adult-for only $2 \%$ of the 20 -second segments that were recorded.

It is not surprising to find that, compared to other team members, young people involved in Wraparound feel less comfortable or satisfied, given it is likely that private details of their lives will be the topic of discussion by the entire team, a group that typically includes five or more team members, most of whom are professional service providers from child-and family-serving systems such as mental health, child welfare, juvenile justice, schools, and so on. In many cases, the young person has been referred to Wraparound precisely because of difficulties or conflicts that involve representatives of these systems. Furthermore, the adults who are present for these team discussions often have access to extensive agency records that may date back for many years. These records describe the young person's service history with the system, usually in ways that highlight pathology, problems, deficits, and crises (e.g., Malysiak 1997; Rosenblatt 1996).

To any young person, the expectation that they will openly disclose personal opinions and informa- 
tion to a group that includes parents and authority figures may well feel unreasonable and intrusive. Adolescents are generally reluctant to disclose personal information to parents or other adults (Daddis and Randolph 2010; Hawk et al. 2009; Masche 2010; Smetana et al. 2009), and this is particularly true among young people with externalizing behavior or general adjustment problems (Daddis and Randolph 2010; Soenens et al. 2006; Stattin and Kerr 2000). What is more, pressuring young people to disclose this kind of information can lead to cycles of conflict and greater secrecy (Hawk et al. 2009; Tilton-Weaver et al. 2010). As described previously, the theory of Wraparound ascribes central importance to the team's ability to elicit the young person's genuine ideas and perspectives. Doing so is clearly a challenge given the potentially adversarial interpersonal context, adolescents' general reluctance to disclose, and the possibility for conflict and alienation from the team to result if the young person feels pressured to provide personal information. The potential for conflict between young people and the team may be even further exacerbated by the fact that adolescents are much less likely than service providers to perceive that there is a need for mental health treatment in the first place, and are very likely to disagree with providers about the problems that need to be addressed (Garland et al. 2003, 2004; Reyes et al. 2015).

The broader research on adolescent development suggests that, in the Wraparound context, additional challenges are likely to arise from efforts to manage and integrate the potentially divergent viewpoints of adolescents and their parents or other caregivers. The principles of Wraparound stress that family and youth perspectives are to be prioritized during the work. The principles also explicitly recognize that the balance of influence needs to be adjusted so that older youth are invited, and indeed encouraged, to become progressively more selfdetermined within the Wraparound process. The re-balancing of decision-making control between youth and parents during adolescence is of course not unique to families in Wraparound (Peterson et al. 1999; Wray-Lake et al. 2010), and the conflict that often attends this transition is well document- ed in families from a wide spectrum of ethnic and cultural backgrounds (Smetana et al. 2009). Simultaneously promoting and managing caregiver and adolescent perspectives may be particularly challenging within Wraparound, since parent-child conflict appears to be pronounced for families with adolescents who have emotional or behavioral disorders (Marmorstein and Iacono 2004). Indeed, engaging in mental health services is itself a potential source of conflict within families, since caregivers and young people often have highly divergent views regarding the need for mental health treatment, its purpose or goals, and its helpfulness (Garland et al. 2004; Hawley and Weisz 2005; Phares and Compas 1990; Phares and Danforth 1994; Reyes et al. 2015).

Taken together, these findings confirm the difficulties that are inherent in engaging young people, their parents or caregivers, and multiple service providers in the type of collaborative planning process described by the Wraparound principles. The findings also suggest that young people's feelings of relative dissatisfaction and lack of participation in Wraparound may be in large part a result of team members' inability to truly engage the young person, and to demonstrate they are aligned with the young person's own views about the goals the team should be pursuing and the best strategies for achieving them. In other words, the findings point to a potential lack of alliance between the young person and the team.

Alliance is a construct that has been extensively studied as a predictor of positive outcomes from psychotherapy (Ardito and Rabellino 2011). Across a number of meta-analyses focused on psychotherapy with adults, alliance-defined as both a positive, supportive bond between client and therapist, and mutual collaboration and agreement between client and therapist on the tasks and goals of therapy-has been shown to have a robust relationship with outcomes, and to explain a greater proportion of the variance in outcomes than many technique factors (Ardito and Rabellino 2011; Zack et al. 2007). While there are far fewer studies of alliance in the context of psychotherapy with adolescents, at least two meta-analyses of studies focused on youth have found a relationship between alliance and out- 
comes of similar magnitude to that found in the studies with adults (Shirk and Karver 2003; Zack et al. 2007). In one study of youth who were receiving community-based mental health outpatient services, youth alliance (as rated by youth themselves) was significantly related to both youth and parent reports of symptom improvement, whereas parent ratings of alliance were not predictive of outcomes (Hawley and Weisz 2005).

In response to the challenges associated with engaging youth in team-based planning, Walker et al. (2012) developed the Achieve My Plan (AMP) intervention as an enhancement to existing Wraparound practice. The AMP intervention was designed using a collaborative process in which research project staff worked together with young people with serious mental health conditions and a history of multi-system involvement, caregivers, and service providers. A pre- post-pilot study of the AMP enhancement intervention (Walker et al. 2012) found that young people's participation and engagement in Wraparound increased significantly across a number of indicators, and that young people's perceptions of their ability to work with providers to optimize their services and supports were higher after AMP was implemented. Furthermore, the study also found that other team members' satisfaction was higher post-AMP, suggesting that increasing youth participation in Wraparound can be accomplished without "crowding out" participation or satisfaction on the part of caregivers or other team members.

The current study used a randomized design to examine various facets of the Wraparound experience for young people receiving as-usual Wraparound, as compared to those receiving Wraparound with the AMP enhancement. The study aimed to test whether or not there were significant differences between the control and intervention groups in terms of various indicators of youth engagement, participation and alliance with the team. The study also examined hypotheses related to the experiences of other team members, including whether any increases in youth participation might be associated with "crowding out," i.e., decreases in other team members' satisfaction or perceptions of the team's productivity.

\section{Method}

\section{Participants}

As is typical elsewhere, children and youth in the state of Oregon are eligible for Wraparound only if they experience very high levels of mental health and related needs (Program Analysis and Evaluation Unit; Oregon Health Authority Office of Health Analytics 2012). They must have, or be at risk for developing, serious emotional, behavioral or substance use disorder, and they must be involved with two or more child-serving systems, most often mental health and child welfare. Youth being served by participating agencies offering Wraparound in the Portland, Oregon metropolitan area were invited to participate in the study based on three criteria: (a) aged 12 to 18 years old, (b) had an active Wraparound treatment plan, and (c) were likely to receive services for at least 6 months. Young people who were eligible for participation were initially approached by their care coordinator, who provided basic information about the research project and found out if the young person had an interest in participating. Some otherwise eligible participants were not approached because the care coordinator-often in consultation with other Wraparound team members-decided that the circumstances of the young person's life made him or her a poor fit for the project (e.g., active crises, scheduled to move out of the area, etc.). Youth who expressed an interest to their care coordinators were invited to participate in an informational session with project staff. All of the youth who participated in these sessions assented to participation in the study. Once young people had assented, their legal guardians were asked to provide consent.

Fifty-five youth were enrolled in this study. Incoming youth who were deemed eligible were randomly assigned to Wraparound care coordinators who had themselves been randomly assigned to either the intervention or comparison group at the outset of the study. Youth in the comparison group participated in Wraparound "as usual," while youth in the intervention group participated in as-usual Wraparound plus the AMP enhancement intervention. 
Of the 55 enrolled youth, 35 were in the intervention group, and 20 were in the comparison group. Among the 35 intervention youth who participated in baseline assessments, 27 participated in assessments at T2 (typically 3-5 weeks after baseline) and 24 at T3. (post intervention). Of the 20 youth in the control condition at T1, 18 participated in assessment at T2 and 17 at T3. The mean age of the study participants at baseline was 14.2 years $(\mathrm{SD}=1.3)$, with females accounting for $42 \%$ of the sample. A little over half of the participants (56\%) identified as White/Caucasian, 18\% as "other," $11 \%$ as Hispanic/Latino/a, 9\% as Black/African American, and $6 \%$ as Asian American. When asked to elaborate, almost all of the youth selecting "other" described themselves as a mix of two or more races from the list. There were no significant differences between the intervention and comparison groups on any of these characteristics.

\section{Procedure}

Intervention. After consent/assent had been secured, participants in the intervention condition met with their AMP coach three times to prepare for the next regularly scheduled Wraparound team meeting, which was referred to as the "target" team meeting. In AMP, the one-on-one coaching meetings are referred to as "prep sessions," and each prep session has a fidelity checklist that the coach and the young person review together at the end of the session to ensure that all of the session elements have been covered.

The first prep session focuses on assisting young people to identify their strengths and longterm goals, and to develop action steps related to one of the goals. A key feature of AMP is that young people are supported in identifying goals that they find personally meaningful and motivating. The goals can be from any life domain and do not need to focus specifically on what other team members or systems might want for, or from, the youth. In fact, from the perspective of AMP, it is not problematic if the young person identifies goals that other team members might not agree with. Often, the long-term goals are not shared with the team at all. However, the AMP coach does help the young person to identify short-term action steps that are related to the goals, and that other team members are likely to support. These action steps are shared with the team.

The second prep session focuses on setting the agenda for the target team meeting. The meeting agenda items are collected from team members prior to this prep session, so that the young people can choose what sections of the agenda they want to lead, and can begin preparing what they would like to say during each section of the agenda. Typically, young people choose to lead the section of the meeting during which they present their proposed action steps, describe their own roles in carrying out the steps, and ask team members for support as needed.

The third prep session focuses on preparing young people to participate actively in all sections of the target meeting. The young people practice what they want to say for the sections they are leading as well as the sections that other team members will lead. The coaches help the young people to anticipate any conflicts that might arise during the meeting, and review strategies for managing these situations. The AMP coach and the young person also develop a plan for support during the meeting so that they will be prepared to respond if the young person becomes angry, anxious, or uncomfortable, or if the young person has trouble remembering what to say. It is important to note that the care coordinator remains responsible for facilitating the team meeting and leading the team process, with the AMP coach in a supporting role focusing on the young person's participation.

During the target meeting, the AMP coach provides the planned support for the young person, prompts the team (as needed) to use best practices for including the youth, and models behaviors that invite youth participation. For example, the AMP coach may remind the team to speak directly to the young person (rather than about him as if he were not in the room), to invite the young person to present her ideas on each topic on the agenda, or to use the parking lot for items that come up in the meeting but for which the young person has not had an opportunity to prepare. The AMP coach may also 
support the care coordinator in recognizing and interrupting common team member behaviors that alienate young people or discourage their participation, such as when team members begin to lecture or badger young people about their plans, ideas or activities.

In between the target team meeting and the next Wraparound team meeting, the coach and the young person meet for two short "booster" sessions to check in about the young person's progress on his/ her goals and action steps, to review what other team members are doing for the plan, and to prepare for the next Wraparound team meeting by repeating the main steps of the three prep sessions. The coach attends this next Wraparound team meeting to support the young person before "handing off" the coaching work to the young person's care coordinator.

AMP coach training. AMP coaches were undergraduate and master's level social work students. The coaches received 6 weeks of training that focused on (a) learning to lead all of the steps that make up the prep sessions and booster sessions and (b) carrying out this work in a manner that ensured that the youth's own ideas and perspectives were driving the work. The process that the trainee coaches participated in included the following steps: reviewing the curriculum with an experienced coach and role-playing interactions; watching videos of experienced AMP coaches as they delivered the curriculum; video recording themselves delivering the AMP curriculum with a "practice" young person (a young person who was not participating in the study); and shadowing an experienced coach. The AMP trainee coaches received feedback on their video-recorded sessions from their supervisor, who was an experienced AMP coach. Trainee coaches continued submitting practice videos until they could deliver the AMP curriculum to fidelity. All of the trainee coaches completed training within the 6-week time frame.

\section{Measures}

The study used three sources of data: assessment surveys, post-meeting surveys, and video recordings of team meetings. All of the survey measures were chosen and, where necessary, adapted based on collaboration with a study advisory group that included young adults with significant experience in mental health systems, as well as service providers and caregivers.

Assessment surveys. Youth and their care coordinators completed online surveys (care coordinators) or in-person or telephone (youth) interviews at three time points: baseline (T1), after the target meeting (usually 3-5 weeks after baseline; T2) and post-intervention (i.e., after two additional Wraparound meetings, usually about 10-12 weeks after baseline; T3). The initial interviews for youth were in-person. Subsequent assessments were either in person or by telephone, depending on youth preferences and placement. The original study design also called for online assessment surveys for caregivers, but caregiver data was discarded due to the youths' frequent placement changes, which meant that in many cases there was not a consistent caregiver to interview. The measures included in the surveys focused on perceptions of meaningful youth participation and engagement in Wraparound. The youth survey also included a measure of mental health empowerment.

Three different aspects of meaningful youth participation in team-based planning were assessed using the three subscales of the Youth Participation in Planning Scale (YPP; Walker and Powers 2007). The YPP was developed by researchers collaboratively with an advisory group of youth and young adults with significant experience in mental health systems. All of the items are rated on a scale from 1 to 5 , with higher scores reflecting greater participation. The planning subscale (8 items, Cronbach's $\alpha=0.90$ ) focuses on the extent to which both the planning process and the plan itself incorporate the youth's ideas and perspectives (e.g., During planning, we make changes to my plan based on my ideas and My plan includes the goals that are most important to $m e$ ). The preparation subscale ( 4 items, $\alpha=0.75$ ) includes items that assess how thoroughly the youth was prepared for the meeting, both in terms of knowing what to expect and planning what and how to contribute to the discussion (e.g., Someone from the team helps me plan the things I want to say at the meeting and Before a team meeting, I am told about 
all the topics that will be on the agenda). The accountability subscale includes 4 items $(\alpha=0.78)$ that focus on the extent to which the young person has access to information about whether or not team members are following up on what they agreed to do during the meeting (e.g., Team members report to me about what they are doing for my plan and Team members have specific tasks to do for my plan). The items on the care coordinator survey were altered so that the focus remained on the youth's participation (e.g., During planning, we make changes to the plan based on the youth's ideas). For each subscale the scores on the individual items were summed and divided by the number of items to produce a mean score that was used in the analyses.

Measures of working alliance assess clients' perceptions that there is a positive and productive relationship between the client and a mental health treatment provider. Working alliance was assessed using items drawn from the Working Alliance Inventory (WAI; Horvath and Greenberg 1989), one of the most commonly used measures of alliance between a client and clinician (Ardito and Rabellino 2011). Ratings are made on a 7 -point scale with higher ratings reflecting greater alliance. The overall alliance is seen as including three aspects: agreement on the goals of the treatment, agreement on the tasks, and the development of a mutual and positive bond. While the WAI has separate subscale scores, the overall score is most commonly used in research studies, and this score has been shown to correlate moderately with treatment outcomes (Martin et al. 2000). Members of the study advisory group identified a subset of WAI items that were seen as most relevant to the Wraparound context, and consulted on adapting the items to reflect alliance with the team as a whole, rather than an individual clinician. For this scale ( 7 items, $\alpha=0.77$ in this study), scores on the individual items were summed and divided by the number of items to produce a mean score that was used in the analyses.

Two of the three subscales from the Youth Empowerment Scale-Mental Health (YES; Walker et al. 2010) were used for the study. All the items on the YES are rated on a 5-point scale, with higher ratings reflecting greater empowerment. The self subscale includes seven items $(\alpha=0.84)$ that are intended to assess a youth's confidence and optimism about coping with and managing a mental health condition (e.g., I make changes in my life so I can live successfully with my emotional or mental health challenges and I know how to take care of my mental or emotional health), while the services subscale ( 7 items, $\alpha=0.85$ ) assesses youths' confidence and capacity to work collaboratively with providers to select and optimize services and supports (e.g., When a service or support is not working for me, I take steps to get it changed and I work with providers to adjust my services and supports so they fit my needs). The final subscale, which was not used, focuses on the system level, and assesses youths' confidence and capacity to help providers improve services and to help other youth understand the service system. For each subscale the scores on the individual items were summed and divided by the number of items to produce a mean score that was used in the analyses.

Post-meeting survey. Post-meeting surveys were collected from all attendees at the target Wraparound team meeting and two subsequent team meetings. The one-page surveys were distributed to attendees at the end of the meeting, then collected and sealed in an envelope and returned to the research team. No names were requested on the survey form. The post meeting survey included a series of items rated on a 4-point scale from yes, definitely to no, definitely not. The items assessed (a) attendees' perceptions of meaningful youth engagement and participation (9 items, e.g., The youth made meaningful choices and decisions for the plan, Goals that are personally meaningful to the youth are part of the plan); (b) attendees' perceptions that important work was being accomplished during the meeting (three items, e.g., We got important planning done, We stuck to the agenda during the meeting); (c) overall satisfaction with the meeting (a single item on a 4-point scale from much worse than usual to much better than usual); and (d) other impressions of the meeting (open-ended questions asking about the best part of the meeting and what could be improved).

A total of 695 post-meeting surveys was collected: 273 at target meetings, 235 at second meetings 
(i.e., the team meetings following target meetings), and 187 at third meetings. Of the total number of surveys, 99 were collected from youth, 144 from caregivers, 100 from care coordinators, 224 from professionals and 128 from people in other roles.

Video recordings. The target meeting was video recorded and then coded using a rating system that scored for the presence of certain features of team interaction and process during each 20-s segment of the recording. Most of the categories focused on aspects of the interaction between the youth and the team. For example, each segment was coded for whether the youth spoke for the whole minute, whether the youth spoke at least three words during the minute, whether the youth made a "high quality" contribution to the discussion (e.g., talked about goals, strategies, strengths or action steps; described events related to a goal, strategy or agenda topic, etc.), whether other team members supported meaningful participation by the youth (e.g., by asking open-ended questions related to the topic under discussion or by inviting the youth to initiate a new topic), and whether the youth and adults were interacting in a positive/supportive or negative/attacking manner. Two coding categories focused on team process: whether the team was on task or not, and whether any team member made a comment about team process (e.g., referred to the agenda, invited a team member to contribute to the discussion or made an observation about the distribution of speaking terms, referred to a ground rule, or referenced an agenda item or the plan sheet). To ensure that videos were coded reliably, coders were trained on practice videos until they were able to match the master coding (i.e., yes or no for each category for each minute of the recording) at about $90 \%$ or better for each coded category. Ongoing reliability checks of the research videos-about half were coded by the most experienced "master" coder as well as another coder-ensured that the level of match averaged above $90 \%$ across categories.

\section{Data Analyses}

Regarding data from the assessment surveys, differences in youth and care coordinator scores for the subscales of the YPP and the team alliance assess- ment were computed for T2-T1 and T3-T1. Each of these differences was entered as the dependent variable in a general linear model with intervention and role as fixed factors. Main effects, as well as the interaction between intervention and role, were included in the models that were tested. In these models, the hypothesis being tested was that the main effect for the intervention was significant and in favor of the intervention (i.e., a one-tailed test of significance was used); and, should the interaction between role and intervention prove significant, that the differences between the means of the control and intervention groups for both roles (youth and care coordinator) were still significant and in favor of the intervention. For the two subscales of the YES, only youth data were collected. Differences in scores were calculated for $\mathrm{T} 2-\mathrm{T} 1$ and $\mathrm{T} 3-\mathrm{T} 1$. The hypothesis in this case was simply that the mean for the youth in the intervention was higher than the mean for youth in the comparison group.

To assess the impact of the intervention on team members' scale scores from the post-meeting survey, and whether that impact varied by role or over time, scale scores were entered as the dependent variable in a general linear model with intervention, meeting number, and role as fixed factors. ("Other" roles were dropped from these analyses due to the heterogeneity of the roles included in the category.) Interactions between role type and intervention and between role type and meeting number were also included in the models. The single item on overall meeting satisfaction was re-coded into a binary variable, with much better than usual as one category and all other responses as the other category. This satisfaction variable was entered as the dependent variable in a logistic regression model with intervention, role type and meeting number as categorical predictors and entered as the first block. The interaction of role type with intervention was entered in the second block.

To analyze the data from the video recordings, percentage occurrence of each coded category was compared for the intervention meetings vs. comparison meetings. One-sided t-tests were used to test the hypotheses that the differences in means would favor the intervention. 
Table 1. Results of general linear models testing differences in means from measures in the assessment survey

\begin{tabular}{|c|c|c|c|c|c|}
\hline & \multicolumn{2}{|c|}{ Main effect: Role $^{a}$} & \multicolumn{2}{|c|}{ Main effect: Intervention } & \multirow{2}{*}{$\begin{array}{l}p \text { value for } \\
\text { intervention }\end{array}$} \\
\hline & Care coordinator & Youth & Comparison & Intervention & \\
\hline YPP Preparation T2-T1 & 0.85 & 0.60 & 0.10 & 1.36 & $0.00^{* *}$ \\
\hline YPP Preparation T3-T1 & 0.43 & 0.27 & 0.00 & 0.69 & $0.00^{* *}$ \\
\hline YPP Planning T2-T1 & 0.31 & 0.34 & -0.01 & 0.65 & $0.00^{* *}$ \\
\hline YPP Planning T3-T1 & 0.14 & 0.11 & -0.14 & 0.38 & $0.00^{* *}$ \\
\hline YPP Accountability T2-T1 & 0.18 & 0.29 & 0.09 & 0.38 & $0.03^{*}$ \\
\hline YPP Accountability T3-T1 & 0.19 & 0.13 & 0.04 & 0.29 & 0.10 \\
\hline Team Alliance T2-T1 & 0.13 & 0.22 & -0.09 & 0.43 & $0.01^{*}$ \\
\hline Team Alliance T3-T1 & 0.14 & 0.47 & 0.08 & 0.52 & $0.03^{*}$ \\
\hline
\end{tabular}

$p$ value after adjustment for false discovery rate ${ }^{\star} p<0.05,{ }^{* *} p<0.01$

${ }^{\text {a }}$ Main effect for role non-significant in all cases

\section{Results}

\section{Assessment Surveys}

None of the dependent variables from the assessment surveys-i.e., subscale scores from the Youth Participation in Planning Scale and Youth Empowerment Scale, and scores from the team alliance assessment-had problems with skewness. Several had kurtosis statistics slightly greater than 1 ; however, this was determined not to be a problem as analysis of variance is robust with respect to kurtosis (DeCarlo 1997).

For the models testing the effect of the intervention on the difference in youth and care coordinator scores on the YPP subscales and the team alliance assessment between $\mathrm{T} 1$ and $\mathrm{T} 2$, and between $\mathrm{T} 1$ and T3, the main effect for the intervention was significant, with the exception of the YPP Accountability subscale between $\mathrm{T} 1$ and $\mathrm{T} 3$ (Table 1). In each case, the effect remained significant after adjusting for multiple comparisons using the correction for false discovery rate (Benjamini and Hochberg 1995).
In only one model, that for the change in scores between T1 and T2 on the YPP planning subscale, was the interaction between intervention and role significant, with the intervention having more of an effect on care coordinators' scores vs. youths'. However, examination of the confidence intervals for the marginal means showed that the mean score for youth in the intervention was still higher than that for youth in the comparison condition. Regarding the models testing for differences between T1 and $\mathrm{T} 2$, and between T1 and T3 for the two subscales of the Youth Empowerment Scale (collected from youth only), while all of the means for the intervention youth were above those for the comparison youth, none of these differences was significant (Table 2).

\section{Post-Meeting Survey}

Reliability for the 9-item scale assessing participants' perceptions of youth participation and engagement was $\alpha=0.86$, and reliability for the 3 -item scale on getting important work done was $\alpha=0.61$. To correct for skew and kurtosis, the scale score 
Table 2. Results of ANOVAs testing differences in means for youth-only measures in the assessment survey

\begin{tabular}{lll}
\hline & Comparison & Intervention $^{\mathrm{a}}$ \\
\hline YES Self T2-T1 & 0.26 & 0.48 \\
YES Self T3-T1 & 0.24 & 0.44 \\
YES Service T2-Y1 & 0.10 & 0.24 \\
YES Service T3-T1 & 0.09 & 0.30 \\
\hline
\end{tabular}

${ }^{\text {a }}$ Differences non-significant in all cases

(computed by taking the average of the item scores) for the participation and engagement scale was reexpressed using a square root transformation as suggested by Tabachnick and Fidell (2012). For the perceptions of participation and engagement scale, all of the main effects (intervention, role, meeting time) were significant $(p<0.01)$, with scores for the intervention higher than those of the comparison group. Neither of the interactions was significant. Post-hoc tests using Tukey's HSD showed that, regarding the main effect by role, youth had significantly higher scale scores than either care coordinators or other professionals, and caregivers had significantly higher scores than care coordinators. Regarding meeting time, post-hoc analyses showed that scores for the third meeting were significantly lower than the first meeting. For the getting important work done scale, only the main effects for intervention and role type were significant $(p<0.01)$, with scores in the intervention group higher than the comparison. Post-hoc tests showed that youth and other professionals had significantly higher scores than care coordinators.

Overall, $52.3 \%$ of the respondents in the intervention group and $32.2 \%$ of the respondents in the comparison rated the meeting as much better than usual. In this model, intervention and role type significantly predicted rating the meeting much better than usual, with respondents in the intervention group 2.35 times more likely to give this rating $(p<0.001)$. Regarding role type, professionals were the least likely of all groups to rate the meeting much better than usual $(p<0.05)$ while youth were more likely than care coordinators (and other professionals) to give the meeting this rating $(p<0.01)$. Inclusion of the interaction in the second block did not improve the model (increase in Nagelkerke $R^{2}<0.02$ ), so the model with only the first block of predictors was retained.

\section{Video Recordings}

In all cases, the differences between the means showed directionality that did indeed favor the intervention; however, this difference was not significant in all cases (Table 3). T-tests were significant for six of the nine team interaction categories and one of the two team process categories. After correction for multiple comparisons using the false discovery rate, the advantage for the intervention was determined to no longer be significant for one of the team interaction categories.

\section{Discussion}

The study findings lend credence to the idea that it is possible, without the infusion of significant additional resources, to significantly increase the extent to which young people are actively engaged and participating in a self-determined manner with their Wraparound teams. Study findings showed that, relative to the comparison condition, young people's active and meaningful participation with the team was greater in the intervention condition according to their own perceptions, according the perceptions of care coordinators and other team members, and according to the evidence from video-recorded team meetings. Additionally, young people in the intervention condition rated their alliance with their Wraparound teams significantly higher than did those in the comparison condition, a finding that is particularly noteworthy given the consistent and significant relationship between alliance and outcomes in mental health treatment studies. The findings also suggest that it is possible to increase the extent to which young people's experience of Wraparound reflects what is prescribed by the Wraparound principles, and to do so in a way that is not detrimental to team productivity 
Table 3. Mean percent occurrence of coded categories from video recordings of Wraparound team meetings

\begin{tabular}{llll}
\hline & & & \\
& Control mean & Intervention mean & $p$-value \\
\hline Youth leads entire segment & 0.02 & 0.06 & $0.01^{*}$ \\
Youth makes significant verbal contribution & 0.41 & 0.52 & 0.04 \\
Team interacts with youth positively & 0.14 & 0.17 & 0.11 \\
Team interacts with youth negatively & 0.04 & 0.02 & 0.12 \\
Youth interacts with team positively & 0.02 & 0.04 & $0.03^{*}$ \\
Youth interacts with team negatively & 0.05 & 0.03 & 0.09 \\
Youth makes a "high quality" contribution & 0.36 & 0.48 & $0.02^{*}$ \\
Team invites "high level" youth contribution & 0.09 & 0.17 & $0.00^{* *}$ \\
Team agrees to act on youth idea & 0.00 & 0.02 & $0.01^{*}$ \\
Team is on task & 0.96 & 0.98 & 0.09 \\
Team member focuses on team process & 0.14 & 0.23 & $0.00^{* *}$ \\
\hline
\end{tabular}

$p$ value after adjustment for false discovery rate ${ }^{* *} p<0.01 ;{ }^{\star} p<0.05$

or the satisfaction of other team members. In fact, compared to the as-usual condition, adult team members in the intervention condition rated team meetings as being significantly more productive, and they were significantly more likely to say that the AMP meetings were "much better than usual" team meetings.

There are of course significant limitations that should be kept in mind when considering the findings from the study. The most obvious of these is connected to the small scale of the study, and the fact that it was conducted within a limited geographical area and in the context of one state's approach to Wraparound implementation. Further research will be needed to see if the findings are generalizable. Additionally, while the study findings provided evidence of an effect on proximal outcomes-satisfaction, participation, alliance, etc. - that have been linked to improvements in symptoms and functioning, the study did not assess symptoms or functioning directly. While increased participation and engagement are not insignificant outcomes from the perspective of the Wraparound principles or theory of change, additional research will be required to test whether these shorter-term impacts will be associated with improvements in longer-term outcomes.

It is worth emphasizing that the AMP coaches-all of whom were undergraduate or master'slevel interns-were able to deliver the intervention in a way that produced these outcomes after having had only 6 weeks of training. The training approach used with the coaches was tightly focused on a set of clearly defined practice steps, skills, and techniques, and on how these "active ingredients" were expected to produce intervention outcomes. Trainees had opportunities to observe experienced coaches-both live and via video recordings. They also made video recordings of their own coaching sessions, and received feedback from experienced coaches that was based on a reliable system for scoring practice and assessing fidelity. The implication is that it may not be all that difficult to train providers to use skills and techniques that can significantly impact youth engagement in mental health services, provided that the intervention is well conceptualized and that 
training reflects evidence-based practices for training transfer (Beidas et al. 2014, 2012; Dorsey et al. 2013; Herschell et al. 2010). This may be particularly helpful in the contexts of principle-driven interventions like Wraparound, since providers often seem to struggle with translating abstract principles into practice (Walker and Flower 2016). It is also worth noting that though the coaches in the study were university interns, the intervention was designed so that the coaching activities could be carried out by Wraparound team members with existing roles on the team, such as care coordinators, peer support providers, or other service providers or paraprofessionals that work directly with young people to promote behavioral skills and/or community inclusion.

The idea that youth engagement can be increased significantly and with relatively low cost becomes more important when considering that Wraparound is only one of a number of similar approaches that are intended to increase young people's self-determined participation in planning processes carried out by teams that include caregivers and service providers. Like Wraparound teams, these teams are tasked with creating comprehensive education, transition, care, or treatment plans for adolescents with mental health conditions and related needs. Typically, these teams are convened for adolescents who are involved with multiple childand family-serving systems, and who are thought to be in need of intensive support. The teams go by many names, including IEP (Individualized Education Plan) teams, foster care Independent Living Program teams, transition planning teams, and youth/family decision teams. Previous studies have provided evidence that young people are often not particularly engaged with these teams, so the possibility of enhancing engagement with a relatively minor investment in training may be attractive beyond the Wraparound context.

A slightly different way of thinking about implications from the study is to focus on the finding that greater alliance between the youth and team was achieved through an intervention that also supported the young person to develop self-determination skills, and to interact with adults and providers in a more self-determined manner. This reflects an understanding of engagement in mental health services that stands in contrast to the way that engagement is most typically defined in studies of efforts to increase it (Kim et al. 2012). In most studies, youth engagement in mental health services is measured by attendance at treatment sessions, which implies a focus on engagement as compliance (since young people rarely choose to attend treatment) rather than engagement through empowerment. Findings from the current study imply that it is possiblewith the use of a set of intentional, empowermentoriented strategies like those contained in the AMP intervention-to create a treatment context that simultaneously promotes connections to caring adults and self-determination/autonomy for young people, specifically including those young people who experience the highest levels of mental health and related needs. Contemporary theory and research on adolescence suggest that young people fare best when they are able to develop increased self-determination while also maintaining connectedness with parents and other adults in their lives (Hawk et al. 2009; Peterson et al. 1999; Smetana et al. 2006, 2003; Wray-Lake et al. 2010).

Existing research suggests that Wraparound, like other mental health services, can act as a crucible in which the developmental challenges and conflicts of adolescence are exacerbated. But when carried out in a way that is consistent with its principles and commitment to youth voice, Wraparound represents a unique opportunity to support adolescents' positive development and manage conflict with caregivers and providers in a way that also promotes positive connections between adolescents and their adults.

\section{References}

Ardito, R. B., \& Rabellino, D. (2011). Therapeutic alliance and outcome of psychotherapy: Historical excursus, measurements, and prospects for research. Frontiers in Psychology, 2, 270.

Beidas, R. S., Cross, W., \& Dorsey, S. (2014). Show me, don't tell me: Behavioral rehearsal as a training and analogue fidelity tool. Cognitive and Behavioral Practice, 21, 1-11. 
Beidas, R. S., Edmunds, J. M., Marcus, S. C., \& Kendall, P. C. (2012). Training and consultation to promote implementation of an empirically supported treatment: A randomized trial. Psychiatric Services, 63, 660-665.

Benjamini, Y., \& Hochberg, Y. (1995). Controlling the false discovery rate: A practical and powerful approach to multiple testing. Journal of the Royal Statistical Society. Series B (Methodological), 57, 289-300.

Bruns, E. J., Walker, J. S., Adams, J., Miles, P., Osher, T. W., \& Rast, J., National Wraparound Initiative Advisory Group. (2004). Ten principles of the Wraparound process. Portland, OR: National Wraparound Initiative, Portland State University.

Bruns, E. J., Walker, J. S., Zabel, M., Matarese, M., Estep, K., Harburger, D., \& Pires, S. A. (2010). Intervening in the lives of youth with complex behavioral health challenges and their families: The role of the Wraparound process. American Journal of Community Psychology, 46, 314-331.

Daddis, C., \& Randolph, D. (2010). Dating and disclosure: Adolescent management of information regarding romantic involvement. Journal of Adolescence, 33, 309-320.

DeCarlo, L. T. (1997). On the meaning and use of kurtosis. Psychological Methods, 2, 292-307.

Dorsey, S., Pullmann, M. D., Deblinger, E., Berliner, L., Kerns, S. E., Thompson, K., \& Garland, A. F. (2013). Improving practice in community-based settings: A randomized trial of supervision-study protocol. Implementation Science, 8, 89.

Garland, A. F., Aarons, G. A., Hawley, K. M., \& Hough, R. L. (2003). Relationship of youth satisfaction with mental health services andchanges in symptoms and functioning. Psychiatric Services, 54,1544-1546.

Garland, A. F., Lewczyk-Boxmeyer, C. M., Gabayan, E. N., \& Hawley, K. M. (2004). Multiple stakeholder agreement on desired outcomes for adolescents' mental health services. Psychiatric Services, 55, 671-676.

Haber, M. G., Cook, J. R., \& Kilmer, R. P. (2012). Perceptions of family environment and Wraparound processes: Associations with age and implications for serving transitioning youth in systems of care. American Journal of Community Psychology, 49, 454-466.
Hawk, S. T., Keijsers, L., Hale, W. W., \& Meeus, W. (2009). Mind your own business! Longitudinal relations between perceived privacy invasion and adolescentparent conflict. Journal of Family Psychology, 23, 511-520.

Hawley, K. M., \& Weisz, J. R. (2005). Youth versus parent working alliance in usual clinical care: Distinctive associations with retention, satisfaction, and treatment outcome. Journal of Clinical Child \& Adolescent Psychology, 34, 117-128.

Herschell, A. D., Kolko, D. J., Baumann, B. L., \& Davis, A. C. (2010). The role of therapist training in the implementation of psychosocial treatments: A review and critique with recommendations. Clinical Psychology Review, 30, 448-466.

Horvath, A. O., \& Greenberg, L. S. (1989). Development and validation of the working alliance inventory. Journal of Counseling Psychology, 36, 223-233.

Kim, H., Munson, M. R., \& McKay, M. M. (2012). Engagement in mental health treatment among adolescents and young adults: A systematic review. Child and Adolescent Social Work Journal, 29, 241-266.

Malysiak, R. (1997). Exploring the theory and paradigm base for Wraparound. Journal of Child and Family Studies, 6, 399-408.

Marmorstein, N. R., \& Iacono, W. G. (2004). Major depression and conduct disorder in youth: Associations with parental psychopathology and parentchild conflict. Journal of Child Psychology and Psychiatry and Allied Disciplines, 45, 377-386.

Martin, D. J., Garske, J. P., \& Davis, M. K. (2000). Relation of the therapeutic alliance with outcome and other variables: A metaanalytic review. Journal of Consulting and Clinical Psychology, 68, 438-450.

Masche, J. G. (2010). Explanation of normative declines in parents' knowledge about their adolescent children. Journal of Adolescence, 33, 271-284.

Peterson, G. W., Bush, K. R., \& Supple, A. (1999). Predicting adolescent autonomy from parents: Relationship connectedness and restrictiveness. Sociological Inquiry, 69, 431-457.

Phares, V., \& Compas, B. E. (1990). Adolescents' subjective distress over their emotional/behavioral problems. Journal of Consulting and Clinical Psychology, 58, 596-603.

Phares, V., \& Danforth, J. S. (1994). Adolescents', parents', and teachers' distress over adolescents' behavior. Journal of Abnormal Child Psychology, 22, 721-732. 
Program Analysis \& Evaluation Unit; Oregon Health Authority Office of Health Analytics. (2012). Statewide children's Wraparound initiative: Fiscal analysis-2009-2011 cost comparisons. Salem, OR: Oregon Health Authority.

Reyes, A. D. L., Augenstein, T. M., Wang, M., Thomas, S. A., Drabick, D. A. G., Burgers, D. E., \& Rabinowitz, J. (2015). The validity of the multi-informant approach to assessing child and adolescent mental health. Psychological Bulletin, 141, 858-900.

Rosenblatt, A. (1996). Bows and ribbons, tape and twine: Wrapping the Wraparound process for children with multi-system needs. Journal of Child and Family Studies, 5, 101-117.

Sather, A., \& Bruns, E. J. (2016). National trends in implementing Wraparound: Results of the state Wraparound survey, 2013. Journal of Child and Family Studies, 25, 3160-3172.

Shirk, S. R., \& Karver, M. (2003). Prediction of treatment outcome from relationship variables in child and adolescent therapy: A meta-analytic review. Journal of Consulting and Clinical Psychology, 71, 452-464.

Smetana, J. G., Campione-Barr, N., \& Metzger, A. (2006). Adolescent development in interpersonal and societal contexts. Annual Review of Psychology, 57, 255-284.

Smetana, J. G., Daddis, C., \& Chuang, S. S. (2003). "Clean your room!": A longitudinal investigation of adolescent-parent conflict and conflict resolution in middle-class African American families. Journal of Adolescent Research, 18, 631-650.

Smetana, J. G., Villalobos, M., Tasopoulos-Chan, M., Gettman, D. C., \& Campione-Barr, N. (2009). Early and middle adolescents' disclosure to parents about activities in different domains. Journal of Adolescence, 32, 693-713.

Soenens, B., Vansteenkiste, M., Luyckx, K., \& Goossens, L. (2006). Parenting and adolescent problem behavior: An integrated model with adolescent self-disclosure and perceived parental knowledge as intervening variables. Developmental Psychology, 42, 305-318.

Stattin, H., \& Kerr, M. (2000). Parental monitoring: A reinterpretation. Child Development, 71, 1072-1085.

Tabachnick, B. G., \& Fidell, L. S. (2012). Using multivariate statistics (6th ed.). New York, NY: Pearson.
Tilton-Weaver, L., Kerr, M., Pakalniskeine, V., Tokic, A., Salihovic, S., \& Stattin, H. (2010). Open up or close down: How do parental reactions affect youth information management? Journal of Adolescence, $33,333-346$.

Walker, J. S., Bruns, E. J., \& Penn, M. (2008). Individualized services in systems of care: The Wraparound process. In B. A. Stroul, \& G. M. Blau (Eds.). The system of care handbook: Transforming mental health services for children, youth, and families. Baltimore, MD: Brookes Publishing.

Walker, J. S., \& Flower, K. (2016). Provider perspectives on principleadherent practice in empirically-supported interventions for emerging adults with serious mental health conditions. Journal of Behavioral Health Services \& Research, 43, 525-541.

Walker, J. S., Geenen, S., Thorne, E., \& Powers, L. E. (2009). Improving outcomes through interventions that increase youth empowerment and self-determination. Focal Point: Research, Policy, and Practice in Children's Mental Health, 23(2), 13-16.

Walker, J. S., \& Matarese, M. (2011). Using a theory of change to drive human resource development for Wraparound. Journal of Child \& Family Studies, 20, 791-803.

Walker, J. S., \& Powers, L. E. (2007). Introduction to the youth selfefficacy scale/mental health and the youth participation in planning scale. Portland, OR: Research and Training Center on Family Support and Children's Mental Health, Portland State University.

Walker, J. S., Pullmann, M. D., Moser, C. L., \& Bruns, E. J. (2012). Does team-based planning "work" for adolescents? Findings from studies of Wraparound. Psychiatric Rehabilitation Journal, 35, 189-197.

Walker, J. S., \& Schutte, K. (2005). Quality and individualization in Wraparound team planning. Journal of Child and Family Studies, 14, 251-267.

Walker, J. S., \& Schutte, K. M. (2004). Practice and process in Wraparound teamwork. Journal of Emotional and Behavioral Disorders, 12, 182-192.

Walker, J. S., Thorne, E. K., Powers, L. E., \& Gaonkar, R. (2010). Development of a scale to measure the empowerment of youth consumers of mental health services. Journal of Emotional and Behavioral Disorders, 18, 51-59. 
Wray-Lake, L., Crouter, A. C., \& McHale, S. M. (2010). Developmental patterns in decision-making autonomy across middle childhood and adolescence: European American parents' perspectives. Child Development, 81, 636-651.
Zack, S. E., Castonguay, L. G., \& Boswell, J. F. (2007). Youth working alliance: A core clinical construct in need of empirical maturity. Harvard Review of Psychiatry, 15, 278-288.

This is an Accepted Manuscript of an article published by Springer in Journal of Child and Family Studies on May 3, 2017, available online: http://link.springer.com/article/10.1007/s10826-017-0738-0

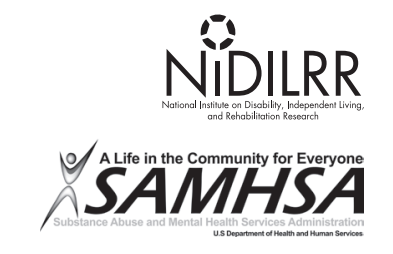

This activity is supported by a grant funded by both the National Institute of Disability, Independent Living, and Rehabilitation Research, and the Center for Mental Health Services Substance Abuse and Mental Health Services Administration, United States Department of Health and Human Services (NIDILRR grant 90RT5030). NIDILRR is a Center within the Administration for Community Living (ACL). The content does not necessarily represent the policy of NIDILRR, ACL, HHS, and you should not assume endorsement by the Federal Government. 